\title{
Temperament, Character, and Adolescents' Depressive Symptoms: Focusing on Affect
}

\author{
Danilo Garcia, ${ }^{1,2}$ Nóra Kerekes, 1, 2,3 \\ Ann-Christine Andersson Arntén, ${ }^{4}$ and Trevor Archer ${ }^{4}$ \\ ${ }^{1}$ Institute of Neuroscience and Physiology, The Sahlgrenska Academy, University of Gothenburg, Wallinsgatan 8, \\ 43141 Gothenburg, Sweden \\ ${ }^{2}$ Centre for Ethics, Law, and Mental Health (CELAM), University of Gothenburg, Wallinsgatan 8, \\ 43141 Gothenburg, Sweden \\ ${ }^{3}$ R\&D Unit, Swedish Prison and Probation Service, Wallinsgatan 8, 43141 Gothenburg, Sweden \\ ${ }^{4}$ Department of Psychology, University of Gothenburg, Box 500, 40530 Gothenburg, Sweden
}

Correspondence should be addressed to Danilo Garcia, danilo.garcia@neuro.gu.se

Received 10 April 2012; Accepted 22 May 2012

Academic Editor: C. Robert Cloninger

Copyright ( 2012 Danilo Garcia et al. This is an open access article distributed under the Creative Commons Attribution License, which permits unrestricted use, distribution, and reproduction in any medium, provided the original work is properly cited.

\begin{abstract}
Positive (PA) and negative affect (NA) are two separate systems markers of subjective well-being and measures of the state depression (low PA combined with high NA). The present study investigated differences in temperament, character, locus of control, and depressive symptoms (sleep quality, stress, and lack of energy) between affective profiles in an adolescent sample. Participants $(N=304)$ were categorized into four affective profiles: "self-fulfilling" (high PA, low NA), "high affective" (high PA, high NA), "low affective" (low PA, low NA), and "self-destructive" (low PA, high NA). Personality was measured by the Temperament and Character Inventory and affective profiles by the Positive Affect and Negative Affect Schedule. The "self-fulfilling" profile was characterized by, compared to the other affective profiles, higher levels of sleep quality, less stress and more energy and also higher levels of persistence and a mature character (i.e., high scores in self-directedness and cooperativeness). "Self-destructive" adolescents reported higher levels of external locus of control, high scores in harm avoidance and reward dependence combined with less mature character. The results identify the importance of character maturity in well-being and suggest that depressive state can be positively influenced by promoting positive emotions which appears to be achieved by character development.
\end{abstract}

\section{Introduction}

Although most would agree in viewing positive and negative affect as opposite ends of a continuum, there is much evidence that they are best construed as two separate systems [1]. For example, the two dimensions are also measures of clinical diagnoses, such as depression, defining it as a mixed state of high negative affect (NA) and low positive affect (PA) [2]. An increase in the frequency of PA and a decrease in the frequency of NA, or a combination of both changes, may lead to an improvement of the depressive symptoms [3]. This simple observation might be crucial regard in adolescence-a period of life when daily problems (e.g., coping with a minor social conflict) seem to be equally stressful experiences as major life events (e.g., parent being remarried) [4].
Moreover, the two dimensions of affect are markers of subjective well-being (SWB), which is usually measured through subjective evaluation and involves both a cognitive and an affective component [5]. Life satisfaction is suggested as the cognitive component and refers to a comparison process in which individuals assess the quality of their lives on the basis of their own self-imposed standard [6]. The affective component of SWB is computed by subtracting the number of NA from the number of PA experienced by the individual, resulting in the so-called affect balance [7]. Seeing the affective component as a unidimensional model, with "ill-being" at one pole and "well-being" at the other, present qualitative differences between individuals that are high compared to low in both dimensions [8].

Along this line of reasoning, some researchers [9-11] have developed the affective personality profiles based on 
self-reported affect measured by the Positive Affect and Negative Affect Schedule [12]. The combinations of these two variables generate four different profiles: self-fulfilling (high PA, low NA); high affective (high PA, high NA); low affective (low PA, low NA); and self-destructive (low PA, high NA). The affective personalities framework goes beyond the view of affect as a two separate systems, taking into account the interaction of both dispositions as recommended by Ito and Cacioppo [8] and also observations of two-system theories suggesting that, when using dichotomous features, combinations must be ruled out [13].

Studies among adults show that self-fulfilling and high affective profiles, compared to low affective and selfdestructive profiles, perform better during stressful situations (e.g., Norlander et al. [9], induced stress using the Stroop Color and Word Test by Stroop [14]) have a more active life (i.e., exercise more often and more intensively). Even in physiological measures differences can be detected, such as they have lower blood pressure $[9,10]$ (see also Kunst [15] who showed that the self-destructive and high affective profiles were strongly associated with increased posttraumatic stress disorder symptoms severity). Nevertheless, while low affective profiles have responded maladaptive to induced stress, compared to self-fulfilling and high affective individuals [9], they have reported less stress in their life as the self-fulfilling profiles [10]. In the context of adolescence, low affective ones seem to avoid stressful situations by neutralizing negative and positive experiences (see Garcia and Siddiqui research [16], for results using the Interpretation and Recognition for Words in a Short Story measure [17], which indicate that low affective adolescents rate negative words in a short story as neutral). Self-fulfilling adolescents, just as adults, report feeling more energetic and optimistic than the other three affective profiles [11].

Moreover, self-acceptance [18, 19], locus of control [20], and self-efficacy [21] are also good predictors of adolescents' affective experience. These constructs are, at least in part, good definitions of character (i.e., concepts of the self, goals, and values) [22]. Although the concept of character holds a major position in psychology, see for example $[23,24]$, most research on happiness (e.g., high PA and low NA) has focused on traits models of personality, for example, the Big Five Model of personality [25].

According to Cloninger's psychobiological model of personality [26], temperament reflects the basic organization of independently different brain systems for the activation, maintenance, and inhibition of behaviour in response to stimuli. Hence, temperament may be responsible for our likes and dislikes or what Haidt [27] calls the "Like-o-Meter". Character is defined as what people make of them selves intentionally or individual differences in prepositional learning of personal goals, values, and even defence mechanisms [22]. Cloninger [22] has suggested that character modifies the significance or meaning of what is experienced, hence also changing emotional reactions and habits. In other words, understanding the self as a unity of being (the self as an autonomous individual, the self as an integral part of humanity or society, and the self as an integral part of the universe) leads to attitudes that increase "personal satisfaction, sublimation, and flexibility regardless of external circumstances" ([22, page 126]; see Table 1 for a closer description of the different dimensions of Cloninger's psychobiological model).

Cloninger's psychobiological model of personality offers important contributions to the understanding of the role of personality on adolescents' emotional experience. Adolescents who seek novel experiences (high novelty seeking) and higher levels of reward (high reward dependence), for example, often engage in risky behaviors, without considering future outcomes or consequences [28], thereby explaining why some extrovert behaviours might be counterproductive and lead to high levels of NA in the context of adolescence. Moreover, self-directedness, a character dimension defined by autonomous and goal-directed behaviour, selfcontrol, and the sense of responsibility is negatively related to NA, while harm avoidance, a temperament dimension characterized by excessive worrying, pessimism, and being fearful, doubtful, and easily fatigued, is positively related to NA [29]. Development of the self in adolescence may be focused on the concept of the self as independent (i.e., selfdirected behaviour) [30] and that specific concept of the self may be another key element to understand the experience of high PA-being able to withstand peer pressure, for instance, gives feelings of personal integrity, honour, selfesteem, effectiveness, leadership, and hope. Such character strengths and feelings may lead to positive affect because they strengthen and prepare the adolescent to cope with different situations [31-34]. More recently, neuroimaging research suggests that cognitive and behavioral changes occurring during adolescence might be understood from the perspective of increased "executive functioning" (e.g., attention, response inhibition, regulation of emotion, organization, and long-range planning; for a review see [35]). This high orders functioning relies on frontal lobe circuitry and represents character maturing.

Accepting that PA and NA are different constructs, the present study investigates differences in temperament, character, locus of control, and symptoms of depression (sleep quality, stress, and lack of energy) between affective personality profiles in an adolescent sample. The hypothesis that self-destructive adolescents report most depressive symptoms compared to their classmates, and that personality profiles (including temperament and character) are distinct descriptive of affective profiles is tested.

\section{Method}

2.1. Participants. The 304 participants (183 boys, 121 girls) were high school pupils from west Sweden $(M=17.34$ years, $\mathrm{SD}=1.16$, range $=16-19)$. They were from different socioeconomic and cultural backgrounds and specializing in different subjects during their studies.

\subsection{Instruments}

Positive Affect and Negative Affect Schedule (PANAS) [12]. The Swedish PANAS version used in the present study has 
TABLE 1: Temperament and character description (reproduced with permission of C. R. Cloninger).

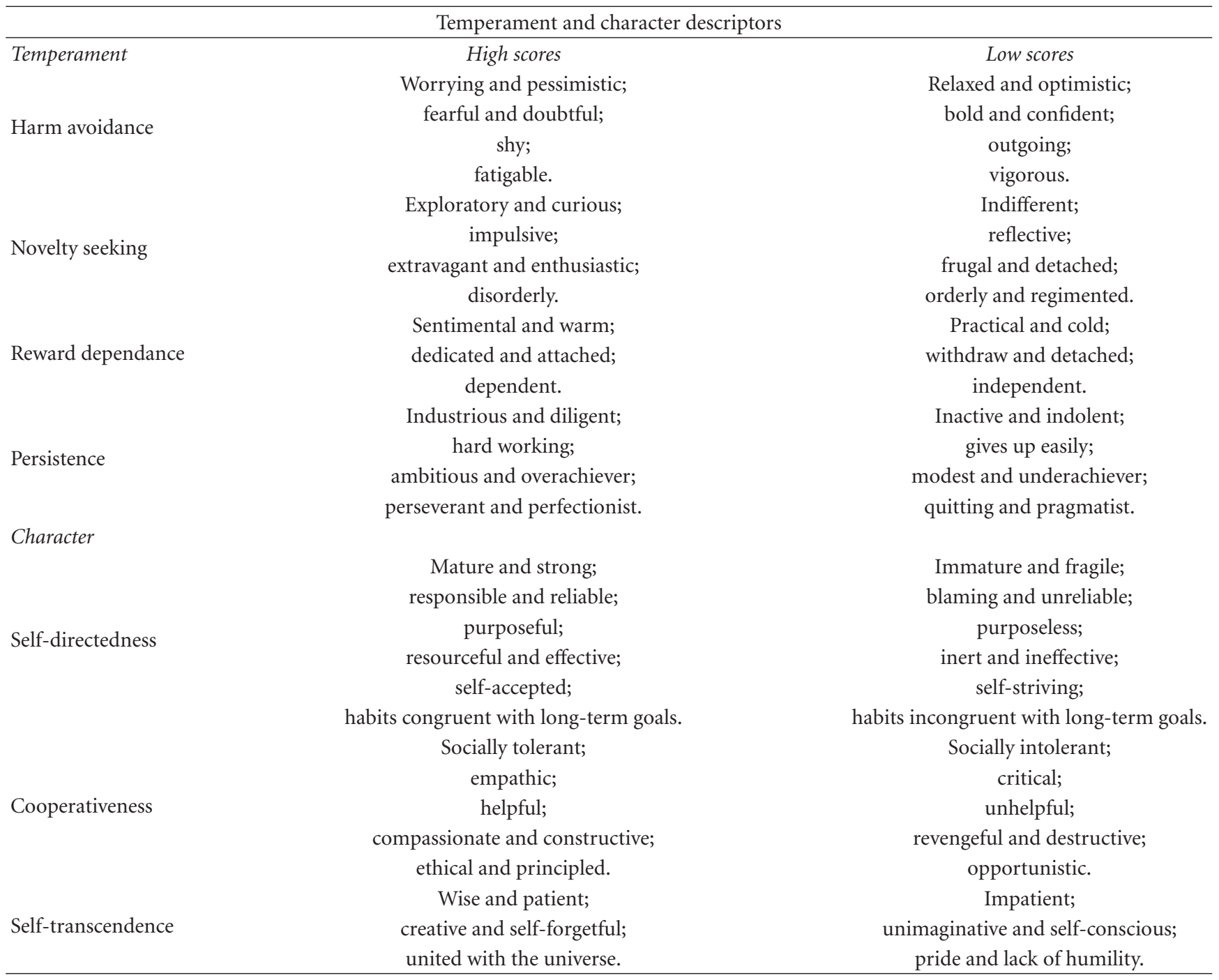

been largely used in other studies among adolescents, for example, [36-39]. The PANAS instructs participants to rate to what extent they generally have experienced 20 different feelings or emotions (10 PA and $10 \mathrm{NA}$ ) for the last four weeks, using a 5 -point Likert scale ( 1 = very slightly, $5=$ extremely). The 10-item PA scale includes adjectives such as strong, proud, and interested. The 10-item NA scale includes adjectives such as afraid, ashamed, and nervous. In the present study, PA showed a Cronbach's $\alpha=.83$ and NA a Cronbach's $\alpha=.83$.

Previous studies [9-11] have modified and developed the PANAS instrument further through a subject-response based derivation of the four types of affective personality profiles. This procedure was implemented in the present study through dividing the results on the PA scale into two parts thereby distributing the participants into one group with high PA and another group with low PA (cut-off point $=53.2 \%$ ). The same procedure was implemented for the participants' responses on the NA-scale (cut-off point = $48.9 \%$ ). Following this, the results from these two scales were combined according to the procedure that assigned each one of the participants into one of the four affective personality groups as follows: individuals showing high PA and low NA (self-fulfilling), high PA and high NA (high affective), low PA and low NA (low affective), and low PA and high NA (selfdestructive).

The Temperament and Character Inventory (TCI) [26]. The TCI measures the seven factors of the psychobiological model of personality with a total of 238 items with forced binary answer (yes or no). The Swedish version of the TCI [40] was used in the present study. The four temperament dimensions are: harm avoidance (e.g., "I often feel tense and worried in unfamiliar situations, even when others feel there is little to worry about"), novelty seeking (e.g., "I often try new things just for fun or thrills, even if most people think it is a waste of time"), reward dependence (e.g., "I like to discuss my experience and feelings openly with friends instead of keeping them to myself"), and persistence (e.g., 
"I often push myself to the point of exhaustion or try to do more than I really can"). The three character dimensions are: self-directedness (e.g., "In most situations my natural responses are based on good habits that I have developed"), cooperativeness (e.g., "I often consider another person's feelings as much as my own"), and self-transcendence (e.g., "I sometimes feel so connected to nature that everything seems to be part of one living organism"). Cronbach's $\alpha$ varied between .69 and .72 in the present study.

Stress and Energy (SE) [41]. The SE instrument is a selfestimation scale, consisting of 12 items that assess individuals' experience of their own stress and energy. The test is divided into two subscales that express each participant's level of mood in the two dimensions: "experienced stress" and "experienced energy". Response alternatives are ordered within 6 points Likert scales $(0=$ not at all, $5=$ very much $)$. The Cronbach's $\alpha$ were .64 for stress and .66 for energy in the present study.

Uppsala Sleep Inventory (USI) [42]. The USI is a selfreport instrument describing participants' sleep profiles, as characterized by descriptions of potential difficulties falling asleep, psychophysiological problems (such as body aches, muscle tension, beating heart, "pins and needles", anxiety feelings, etc.), and larger sleep problems. Here five response alternatives were available: "none", "a little", "about average", "large", and "very great". The Cronbach's $\alpha$ were .71 for major sleep problems, .75 for difficulties falling asleep, and .72 for psychophysiological problems.

Locus of Control [43]. The Locus of Control scale is a modified version of the original Rotter scale [44]. The scale has a minimum score of 8 and a maximum of 40 , with a lower score representing an external locus of control orientation and a higher score representing an internal locus of control orientation.

2.3. Procedure. All adolescents in the study had written parental consent. If parents wanted any further information about the study, they were asked to contact the researchers. All adolescents received cinema tickets for their anonymous participation.

For statistical analyses the multiple analysis of variance (MANOVA) test was applied in order to identify differences in depressive symptoms and personality between affective profiles, during what the affective profile was the independent variable and the dependent variables were depressive symptoms (i.e., levels of stress and energy, sleep problems, difficulties falling asleep, psychophysiological problems), personality (measured by the TCI), and locus of control (external and internal).

\section{Results}

The four defined affective profiles were characterized with different patterns of depressive symptoms. A significant effect emerged for levels of stress $(F(3,321)=19.03$,
$P<.001)$, energy $(F(3,321)=20.31, P<.001)$, large sleep problems $(F(3,321)=18.01, P<.001)$, difficulties falling asleep $(F(3,318)=24.45, P<.001)$, and for psychobiological problems $(F(3,321)=11.19, P<.001)$. Self-fulfilling adolescents reported significantly higher level of energy as well as in all cases lower (in most cases significantly lower) levels of stress, sleep, or psychobiological problems (Table 2). The group of high affective ones differed mostly from selfdestructive ones in their increased energy. The low affective adolescents differed mostly from the self-destructive ones in their decreased level of stress and psychobiological problems.

In regard to personality profiles describing the four affective group self-fulfilling adolescents were characterized with significantly lower harm avoidance $(F(3,303)=23.30$, $P<.001)$, and significantly higher persistence $(F(3,303)=$ 7.63, $P<.001)$, than the other three groups of youngsters. Moreover, they possessed a more mature character, measured with significantly higher scores in TCI self-directedness $(F(3$, $303)=20.55, P<.001)$ and TCI cooperativeness $(F(3$, $303)=2.59, P=.05)$. On the other side, high affective and self-destructive groups were described by high reward dependence. Low-affective adolescents differed mostly in lower self-transcendence $(F(3,303)=6.61, P<.001)$ from their high affective classmates. Adolescents with a selfdestructive profile reported higher external locus of control $(F(3,317)=9.07, P<.001)$ while no differences emerged for internal locus of control $(F(3,320)=1.30, P=.263)$ between any of the four groups (Table 3 ).

\section{Discussion}

In the present study, we tested the hypothesis that selfdestructive adolescents report most depressive symptoms compared to their classmates, and that personality profiles (including temperament and character) are distinct descriptive of affective profiles. The results showed that adolescents expressing a self-fulfilling profile (i.e., high PA and low NA) report higher levels of sleep quality, less stress, and more energy than the other three profiles and had a more mature character and were more persistent. As suggested in the introduction, adolescents who seek novel experiences and higher levels of reward often engage in risky behaviours, without considering future outcomes or consequences [28]. In contrast, character strengths may lead to positive emotions because they strengthen and prepare the adolescent to cope with different situations [22, 31]. Although Cloninger [22] describes possible risks throughout life for persons with special combinations of "difficult temperament" mediated by psychosocial conflicts, the temperament is assumed to have a more pathoplastic effect while the character development is the key to understand and evaluate health. Recently, Brown and colleagues [45] found that, among adolescents, PA was positively correlated with mindfulness measured with Mindful Attention Awareness Scale Adolescent. Mindfulness, in turn, was positively related to higher life satisfaction and wellness. In day-to-day life, mindfulness is an awareness of the presence and a conscious processing based on experience [46]. Positive affect has also been found to be related to and associated with better stress handling [9, 47], better 
TABLE 2: Mean ( \pm SD) scores for stress, energy, large sleep problems, difficulties falling asleep, and psychobiological problems among affective profiles.

\begin{tabular}{lcccc}
\hline & $\begin{array}{c}\text { Self-fulfilling } \\
\text { (high PA and low NA) }\end{array}$ & $\begin{array}{c}\text { High affective } \\
\text { (high PA and high NA) }\end{array}$ & $\begin{array}{c}\text { Low affective } \\
\text { (low PA and low NA) }\end{array}$ & $\begin{array}{c}\text { Self-destructive } \\
\text { (low PA and high NA) }\end{array}$ \\
\hline Energy & $30.49 \pm .86^{*}$ & $26.02 \pm .89$ & $23.90 \pm .88$ & $21.70 \pm .73$ \\
Stress & $15.94 \pm .99$ & $20.16 \pm 1.13^{\mathbf{\Delta}}$ & $16.04 \pm .86$ & $26.50 \pm 1.15^{\mathbf{\Delta}}$ \\
Major sleep problems & $15.50 \pm 4.20$ & $19.30 \pm 4.19^{\mathbf{\Delta}}$ & $17.30 \pm 4.69^{\mathbf{\Delta}}$ & $19.95 \pm 4.86^{\mathbf{\Delta}}$ \\
Difficulties falling asleep & $17.42 \pm 4.29$ & $21.34 \pm 4.96^{\boldsymbol{\Delta}}$ & $18.52 \pm 4.88$ & $23.52 \pm 6.49^{\mathbf{\Delta}}$ \\
Psychophysiological problems & $20.61 \pm .93$ & $25.63 \pm 1.07^{\mathbf{\Delta}}$ & $24.06 \pm 1.09^{\mathbf{\Delta}}$ & $29.24 \pm 1.09^{\mathbf{\Delta}}$ \\
\hline
\end{tabular}

$N=304,{ }^{*}$ higher than the other three groups, $\mathbf{\Delta}$ higher than self-fulfilling.

TABLE 3: Mean $( \pm S D)$ scores for temperament, character, and locus of control among affective profiles.

\begin{tabular}{lcccc}
\hline & $\begin{array}{c}\text { Self-fulfilling } \\
\text { (high PA and low NA) }\end{array}$ & $\begin{array}{c}\text { High affective } \\
\text { (high PA and high NA) }\end{array}$ & $\begin{array}{c}\text { Low affective } \\
\text { (low PA and low NA) }\end{array}$ & $\begin{array}{c}\text { Self-destructive } \\
\text { (low PA and high NA) }\end{array}$ \\
\hline Novelty seeking & $56.06 \pm 1.45$ & $56.34 \pm 1.58$ & $55.37 \pm 1.51$ & $54.31 \pm 1.53$ \\
Harm avoidance & $33.22 \pm 1.79$ & $42.92 \pm 1.35^{\mathbf{\Delta}}$ & $45.19 \pm 1.80^{\mathbf{\Delta}}$ & $54.97 \pm 1.93^{\mathbf{\Delta}}$ \\
Reward dependence & $53.31 \pm 1.48$ & $56.58 \pm 1.61^{\mathbf{\Delta}}$ & $52.17 \pm 1.55$ & $57.06 \pm 1.72^{\mathbf{\Delta}}$ \\
Persistence & $59.38 \pm 2.52^{*}$ & $53.31 \pm 2.72$ & $43.50 \pm 2.47$ & $44.11 \pm 2.41$ \\
Self-directedness & $65.62 \pm 1.45^{*}$ & $58.02 \pm 1.27$ & $60.43 \pm 1.73$ & $48.30 \pm 1.57$ \\
Cooperativeness & $69.37 \pm 1.39^{*}$ & $67.13 \pm 1.54$ & $65.95 \pm 1.59$ & $63.05 \pm 1.68$ \\
Self-transcendence & $39.42 \pm 1.87$ & $48.61 \pm 1.78^{\bullet}$ & $34.77 \pm 1.61$ & $41.76 \pm 1.73$ \\
External locus of control & $7.11 \pm 2.15$ & $9.21 \pm 2.33$ & $7.25 \pm 2.56$ & $14.49 \pm 2.32^{\mathbf{\Delta}}$ \\
Internal locus of control & $12.71 \pm 2.37$ & $12.65 \pm 2.88$ & $12.41 \pm 2.59$ & $12.02 \pm 2.46$ \\
\hline
\end{tabular}

$N=304,{ }^{*}$ higher than the other three groups, $\mathbf{\Delta}$ higher than self-fulfilling, ${ }^{\bullet}$ higher than low affective.

sleep quality [48], and better coping resources [10, 47]. Even momentarily PA can be associated with such positive effects as survival in elderly people [49]. Together, these findings indicate that PA is associated with a more "mature" and health related character in adolescence.

In the present study, this mature character was defined by a higher autonomous self-concept (i.e., high in selfdirectedness) and a tendency to be more socially adapted (i.e., high cooperativeness). A self-directed adolescent might be described as mature and strong, responsible and reliable, purposeful, resourceful and effective, and selfaccepted [22]. Similarly, an adolescent expressing high level of cooperativeness is socially tolerant, empathic, helpful, compassionate, and constructive [22]. Thus, interventions that promote such types of behaviours and attitudes to the self should be encouraged at home and in schools. Brown et al. [45] and Teasdale [46] suggests that interventions influencing adolescents to give and receive help (e.g., peer counselling) strengthens self-acceptance and fosters adolescents' capacity to experience moments of happiness and identity formation. The benefits from such interventions are greater "self-esteem, sense of purpose and worth, feeling of accomplishment and mastery, and satisfying interaction with other humans beings [sic]" [50, page 192]. These benefits are, at least in part, a good definition of selfdirectedness. With respect to self-transcendence, Magen's research suggests that adolescents address simple forms of this self-concept. Moreover, adolescents' pursuit of positive emotions tend to be egocentric and directed by their own desires [51]. Thus, these tendencies may be contradictory to the willingness to become dedicated to the well-being of others or prosocial causes that transcend the self [51]. Nevertheless, our findings show that high scores in the selftranscendence dimension might be related to high affectivity during adolescence.

Locus of control may be viewed as a prevailing expectancy, perceptions/cognitions that allow the evaluation of situations and circumstances. Individuals characterised by an internal locus of control (internals) believe that they control their own fate whereas those characterised by external locus of control (externals) are convinced that chance, luck, the stars, or behaviour of others determine the course of their lives. In the present study, individuals expressing self-fulfilling behaviour expressed markedly less (less than half) external locus of control than individuals expressing self-destructive. This observation associates high levels of external locus of control with depressive tendencies. Previously, in three different studies, Archer and colleagues [52] showed that external locus of control was predicted by NA and counter-predicted by PA and optimism. Higher scores of NA have also been found to be associated with a more externally based locus of control and a lower overall level of self-esteem among adolescents [53]. Marklund [54] obtained a strong positive correlation between "externals" and urgency (a factor involving impulsiveness) which implies that these individuals showed "difficulties resisting desires" and "temptations" together with the tendency to resort to impulsive behaviours in order to alleviate negative emotions; 
these observations imply also that an "external" strategy in viewing events relates notably to temperament. Generally, "externals" express lower levels of satisfaction and rehabilitation and lesser health benefits compared to "internals" [52].

4.1. Limitations and Further Questions. Although the instruments used to measure PA and NA showed high reliability, appropriate measures for the two constructs have been developed and validated for use with adolescents (e.g., the PANAS-C) [55]. Nevertheless, evidence of the reliability and validity of the PANAS in adolescents can be found elsewhere [56]. It is also important to mention that there is a version for measuring the seven factors of Cloninger's personality model among youth: the Junior Temperament and Character Inventory (JTCI). However, the JTCI was developed for use with children between the ages of 9 and 13 [57]. The version of the TCI used in the present study was found more appropriate because the participants in the present study were high-school pupils with an age range from 16 to 19 .

Studies among preadolescent children may supply important insights of adolescents' depressiveness and related symptoms since predictors of behavioural problems that persist from adolescence to adulthood (e.g., conduct problems) are best assessed prior to adolescence [58]. Neurodevelopmental aspects of affective disorders draw attention to adverse environmental influences during early and late childhood that need to be addressed [59].

\section{Conclusions}

The results presented here show an expected and well matching nomological network between the measures indicating a chance to influence a depressive state in a positive way by promoting positive emotions as well as encourage character maturation. With an investment in increasing character maturity in adolescents, an increase in life energy and decrease in less sleep and psychosocial problems could be achieved. These results together with other evidences from studies applying PANAS and TCI [60-62] suggest that the affective personality profiles provide clues regarding the emotional, cognitive, motivational, and somatic categories of well-being states.

"Temperament lies behind mood; behind will, lies the fate of character. Then behind both, the influence of family the tyranny of culture; and finally the power of climate and environment; and we are free, only to the extent we rise above these." John Burroughs

\section{Acknowledgments}

The authors would like to thank the Stiftelsen KempeCarlgrenska Fonden for supporting the development of this paper. The authors want to also thank the participants and their families.

\section{References}

[1] A. MacLeod and R. Moore, "Positive thinking revised: positive cognitions,well-being and mental health," Clinical Psychology and Psychotherapy, vol. 7, no. 1, pp. 2-10, 2000.

[2] L. A. Clark and D. Watson, "Tripartite model of anxiety and depression: psychometric evidence and taxonomic implications," Journal of Abnormal Psychology, vol. 100, no. 3, pp. 316336, 1991.

[3] D. J. Needles and L. Y. Abramson, "Positive life events, attributional style, and hopefulness: testing a model of recovery from depression," Journal of Abnormal Psychology, vol. 99, no. 2, pp. 156-165, 1990.

[4] G. McCullough, E. S. Huebner, and J. E. Laughlin, "Life events, self-concept, and adolescents' positive subjective well-being," Psychology in the Schools, vol. 37, no. 3, pp. 281-290, 2000.

[5] W. Pavot, "The assessments of subjective well-being," in The Science of Subjective Well-Being, M. Eid and R. J. Larsen, Eds., pp. 124-140, The Guilford Press, New York, NY, USA, 2008.

[6] W. Pavot and E. Diener, "Review of the satisfaction with life scale," Psychological Assessment, vol. 5, no. 2, pp. 164-172, 1993.

[7] U. Schimmack and E. Diener, "Affect intensity: separating intensity and frequency in repeatedly measured affect," Journal of Personality and Social Psychology, vol. 73, no. 6, pp. 13131329, 1997.

[8] A. T. Ito and J. T. Cacioppo, "Affect and attitudes: a social neuroscience approach," in Handbook of Affect and Social Cognition, J. P. Forgas, Ed., pp. 50-74, Erlbaum, New Jersey, NJ, USA, 2001.

[9] T. Norlander, S. Å. Bood, and T. Archer, "Performance during stress: affective personality, age, and regularity of physical exercise," Social Behavior and Personality, vol. 30, no. 5, pp. 495-508, 2002.

[10] T. Norlander, A. Johansson, and S. A. Bood, "The affective personality: its relation to quality of sleep, well-being and stress," Social Behavior and Personality, vol. 33, no. 7, pp. 709722, 2005.

[11] T. Archer, L. Adrianson, A. Plancak, and E. Karlsson, "Influence of affective personality on cognition-mediated emotional processing: need for empowerment," European Journal of Psychiatry, vol. 21, no. 4, pp. 21-44, 2007.

[12] D. Watson, L. A. Clark, and A. Tellegen, "Development and validation of brief measures of positive and negative affect: the PANAS scale," Journal of Personality and Social Psychology, vol. 54, no. 6, pp. 1063-1070, 1988.

[13] G. Keren and Y. Schul, "Two is not always better than one. A critical evaluation of two-system theories," Perspectives on Psychological Science, vol. 4, pp. 533-550, 2009.

[14] J. R. Stroop, "Studies of interference in serial verbal reactions," Journal of Experimental Psychology, vol. 18, no. 6, pp. 643-662, 1935.

[15] J. J. M. Kunst, "Affective personality type, post-traumatic stress disorder symptom severity and post-traumatic growth in victims of violence," Stress and Health, vol. 27, no. 1, pp. 42-51, 2011.

[16] D. Garcia and A. Siddiqui, "Adolescents' affective temperaments: life satisfaction, interpretation, and memory of events," The Journal of Positive Psychology, vol. 4, no. 2, pp. 155-167, 2009.

[17] D. Garcia, "Interpretation and Recognition for Words in a Short Story (IRWSS)," At the American Psychology Association's PsycTESTS Database. 
[18] D. Garcia and A. Siddiqui, "Adolescents' psychological wellbeing and memory for life events: influences on life satisfaction with respect to temperamental dispositions," Journal of Happiness Studies, vol. 10, no. 4, pp. 407-419, 2009.

[19] D. Garcia and S. Moradi, "Adolescents' temperament and character: a longitudinal study on happiness," Journal of Happiness Studies. In press.

[20] C. Ash and E. S. Huebner, "Environmental events and life satisfaction reports of adolescents: a test of cognitive mediation," School Psychology International, vol. 22, no. 3, pp. 320-336, 2001.

[21] L. M. Fogle, E. S. Huebner, and J. E. Laughlin, "The relationship between temperament and life satisfaction in early adolescence: cognitive and behavioral mediation models," Journal of Happiness Studies, vol. 3, pp. 373-392, 2002.

[22] C. R. Cloninger, Feeling Good: The Science of Well-Being, Oxford University Press, New York, NY, USA, 2004.

[23] G. W. Allport, Becoming: Basic Considerations for a Psychology of Personality, Yale University Press, New Haven, Conn, USA, 1955.

[24] C. R. Rogers, "A theory of therapy, personality, and interpersonal relationships, as developed in the client-centered framework," in Psychology: A Study of a Science, S. Koch, Ed., vol. 3, pp. 184-256, McGraw-Hill, New York, NY, USA, 1959.

[25] P. T. Costa Jr. and R. R. McCrae, "NEO PI-R professional manual," Psychological Assessment Resources, Odessa, Ukraine, 1992.

[26] C. R. Cloninger, D. M. Svrakic, and T. R. Przybeck, "A psychobiological model of temperament and character," Archives of General Psychiatry, vol. 50, no. 12, pp. 975-990, 1993.

[27] J. Haidt, The Happiness Hypothesis: Finding Modern Truth in Ancient Wisdom, Basic Books, New York, NY, USA, 2006.

[28] A. E. Kelley, T. Schochet, and C. F. Landry, "Risk taking and novelty seeking in adolescence: introduction to part I," Annals of the New York Academy of Sciences, vol. 1021, pp. 27-32, 2004.

[29] M. Asch, S. Cortese, F. P. Diaz et al., "Psychometric properties of a French version of the junior temperament and character inventory," European Child and Adolescent Psychiatry, vol. 18, no. 3, pp. 144-153, 2009.

[30] E. H. Erikson, Identity: Youth and Crisis, Norton, New York, NY, USA, 1968.

[31] M. E. P. Seligman, Authentic Happiness: Using the New Positive Psychology to Realize Your Potential for Lasting Fulfilment, Free Press, New York, NY, USA, 2002.

[32] C. R. Cloninger, "Fostering spirituality and well-being in clinical practice," Psychiatric Annals, vol. 36, no. 3, pp. 1-6, 2006.

[33] D. Garcia, "Two models of personality and well-being among adolescents," Personality and Individual Differences, vol. 50, no. 8, pp. 1208-1212, 2011.

[34] D. Garcia, "The affective temperaments: differences between adolescents in the big five model and cloninger's psychobiological model of personality," Journal of Happiness Studies. In press.

[35] J. N. Giedd, "The teen brain: insights from neuroimaging," Journal of Adolescent Health, vol. 42, no. 4, pp. 335-343, 2008.

[36] D. Garcia and T. Archer, "Adolescent life satisfaction and wellbeing," Journal of Alternative Medicine Research. In press.

[37] D. Garcia, T. Archer, S. Moradi, and A.-C. Andersson-Arntén, "Exercise frequency, high activation positive affectivity, and psychological well-being: beyond age, gender, and occupation," Psychology, vol. 3, pp. 328-336, 2012.
[38] D. Garcia and A. Erlandsson, "The relationship between personality and subjective well-being: different association patterns when measuring the affective component in frequency and intensity," Journal of Happiness Studies, vol. 12, no. 6, pp. 1023-1034, 2011.

[39] D. Garcia, P. Rosenberg, A. Erlandsson, and A. Siddiqui, "On lions and adolescents: affective temperaments and the influence of negative stimuli on memory," Journal of Happiness Studies, vol. 11, no. 4, pp. 477-495, 2010.

[40] S. Brändström, P. Schlette, T. R. Przybeck et al., "Swedish normative data on personality using the temperament and character inventory," Comprehensive Psychiatry, vol. 39, no. 3, pp. 122-128, 1998.

[41] T. Archer, B. Adolfsson, and E. Karlsson, "Affective personality as cognitive-emotional presymptom profiles regulatory for self-reported health predispositions," Neurotoxicity Research, vol. 14, no. 1, pp. 21-44, 2008.

[42] J. Hetta, M. Almqvist, H. Agren, G. Hambert, G. B. Liljenberg, and B. E. Roos, "Prevalence of sleep disturbances and related symptoms in a middle-aged Swedish population," in Sleep '84, W. P. Koella, E. Ruther, and H. Schultz, Eds., pp. 373-376, Gustaf Fischer Förlag, Stuttgart, Germany, 1985.

[43] P. Millet and K. Sandberg, "Locus of control and its relationship with vocational rehabilitation of unemployed sick leaves in Sweden," Journal of Vocational Rehabilitation, vol. 19, no. 1, pp. 59-66, 2003.

[44] J. B. Rotter, "Generalized expectancies for internal versus external control of reinforcement," Psychological Monographs, vol. 80, no. 1, pp. 1-28, 1966.

[45] K. W. Brown, A. M. West, T. M. Loverich, and G. M. Biegel, "Assessing adolescent mindfulness: validation of an adapted mindful attention awareness scale in adolescent normative and psychiatric populations," Psychological Assessment, vol. 23, pp. 1023-1033, 2011.

[46] J. D. Teasdale, "Emotional processing, three modes of mind and the prevention of relapse in depression," Behaviour Research and Therapy, vol. 37, no. 1, pp. S53-S77, 1999.

[47] A.-C. Andersson-Arntén, B. Jansson, and T. Archer, "Influence of affective personality type and gender upon coping behavior, mood, and stress," Individual Differences Research, vol. 6, no. 3, pp. 139-168, 2008.

[48] T. Norlander, A. Johansson, and S.-A. Bood, "The affective personality: its relation to quality of sleep, well-being and stress," Social Behavior and Personality, vol. 33, no. 7, pp. 709722, 2005.

[49] A. Steptoe and J. Wardle, "Positive affect measured using ecological momentary assessment and survival in older men and women," Proceedings of the National Academy of Sciences, vol. 108, pp. 18244-18248, 2011.

[50] Z. Magen, "Commitment beyond self and adolescence: the issue of happiness," Social Indicators Research, vol. 37, no. 3, pp. 235-267, 1996.

[51] Z. Magen, Exploring Adolescent Happiness. Commitment, Purpose and Fulfillment, Sage Publications, London, UK, 1998.

[52] T. Archer, B. Adolfsson, and E. Karlsson, "Affective personality as cognitive-emotional presymptom profiles regulatory for self-reported health predispositions," Neurotoxicity Research, vol. 14, no. 1, pp. 21-44, 2008.

[53] E. S. Huebner and R. Dew, "Preliminary of the positive and negative affect scale with adolescents," Journal of Psychoeducational Assessment, vol. 13, pp. 286-293, 1995.

[54] K. Marklund, "Impulsiveness as a multifaceted construct. A psychometric study of the UPPS-scale and the association 
between impulsiveness and the experience of control," University of Stockholm, Department of Psychology Graduate Reports, 2008.

[55] J. Laurent, S. J. Catanzaro, T. E. Joiner et al., "A measure of positive and negative affect for children: scale development and preliminary validation," Psychological Assessment, vol. 11, no. 3, pp. 326-338, 1999.

[56] G. McCullough, E. S. Huebner, and J. M. Laughlin, "Life events, self-concept, and adolescents' positive subjective wellbeing," Psychology in the Schools, vol. 37, no. 3, pp. 281-290, 2000.

[57] J. L. Luby and D. M. Svrakic, "The junior temperament and character inventory: preliminary validation of a child selfreport measure," Psychological Reports, vol. 84, no. 3, pp. 1127$1138,1999$.

[58] L. Steinberg and A. S. Morris, "Adolescent development," Annual Review of Psychology, vol. 52, pp. 83-110, 2001.

[59] T. Archer, R. M. Kostrzewa, R. J. Beninger, and T. Palomo, "Staging perspectives in neurodevelopmental aspects of neuropsychiatry: agents, phases and ages at expression," Neurotoxicity Research, vol. 18, no. 3-4, pp. 287-305, 2010.

[60] C. R. Cloninger and A. H. Zohar, "Personality and the perception of health and happiness," Journal of Affective Disorders, vol. 128, no. 1-2, pp. 24-32, 2011.

[61] D. Garcia and S. Moradi, "The affective temperaments and well-being: Swedish and Iranian adolescents' life satisfaction and psychological well-being," Journal of Happiness Studies. In press.

[62] D. Garcia, N. Kerekes, and T. Archer, "A will anda proper way leading to happiness: self-directedness mediates the effect of persistence on positive affectivity," Personality and Individual Differences. In press. 


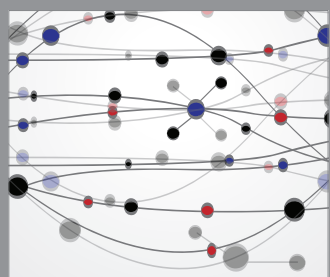

The Scientific World Journal
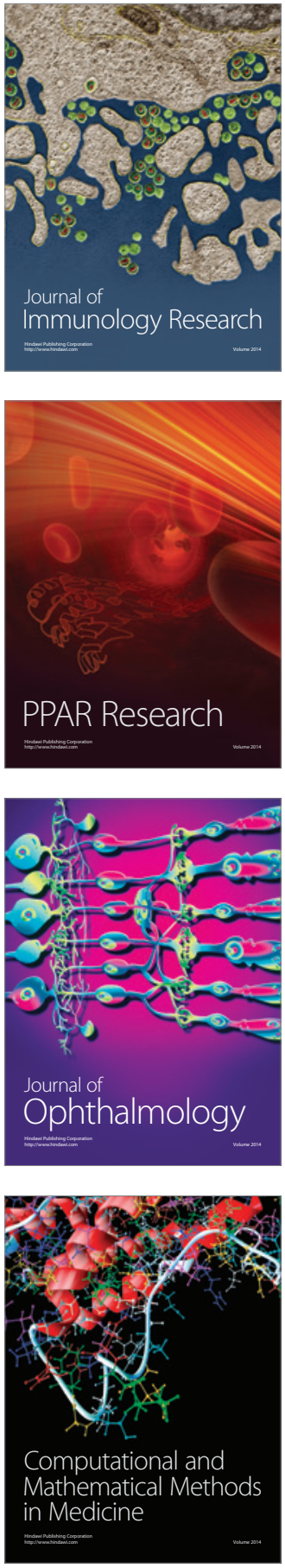

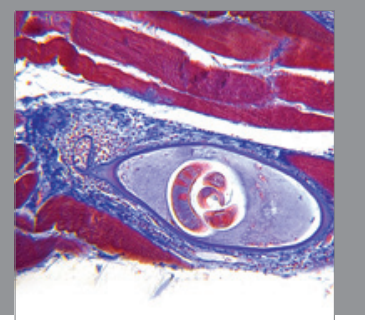

Gastroenterology

Research and Practice
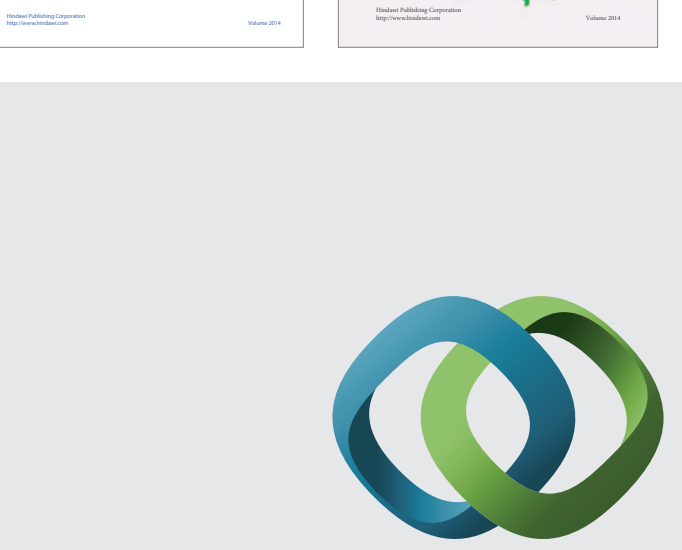

\section{Hindawi}

Submit your manuscripts at

http://www.hindawi.com
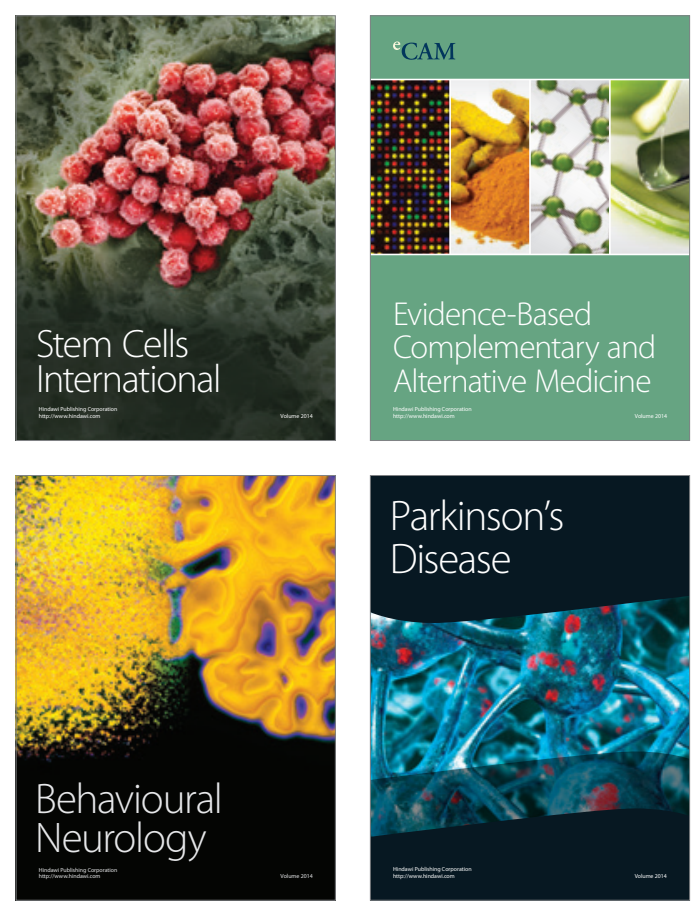

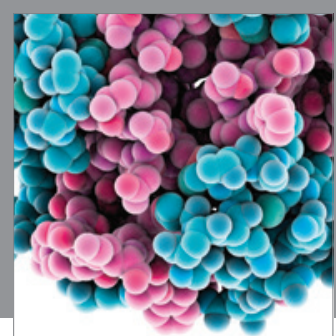

Journal of
Diabetes Research

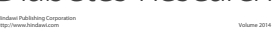

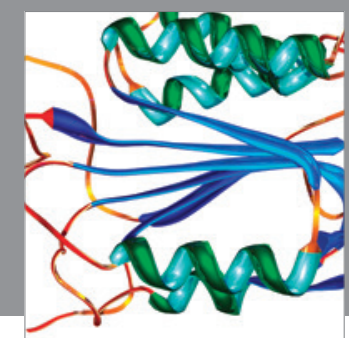

Disease Markers
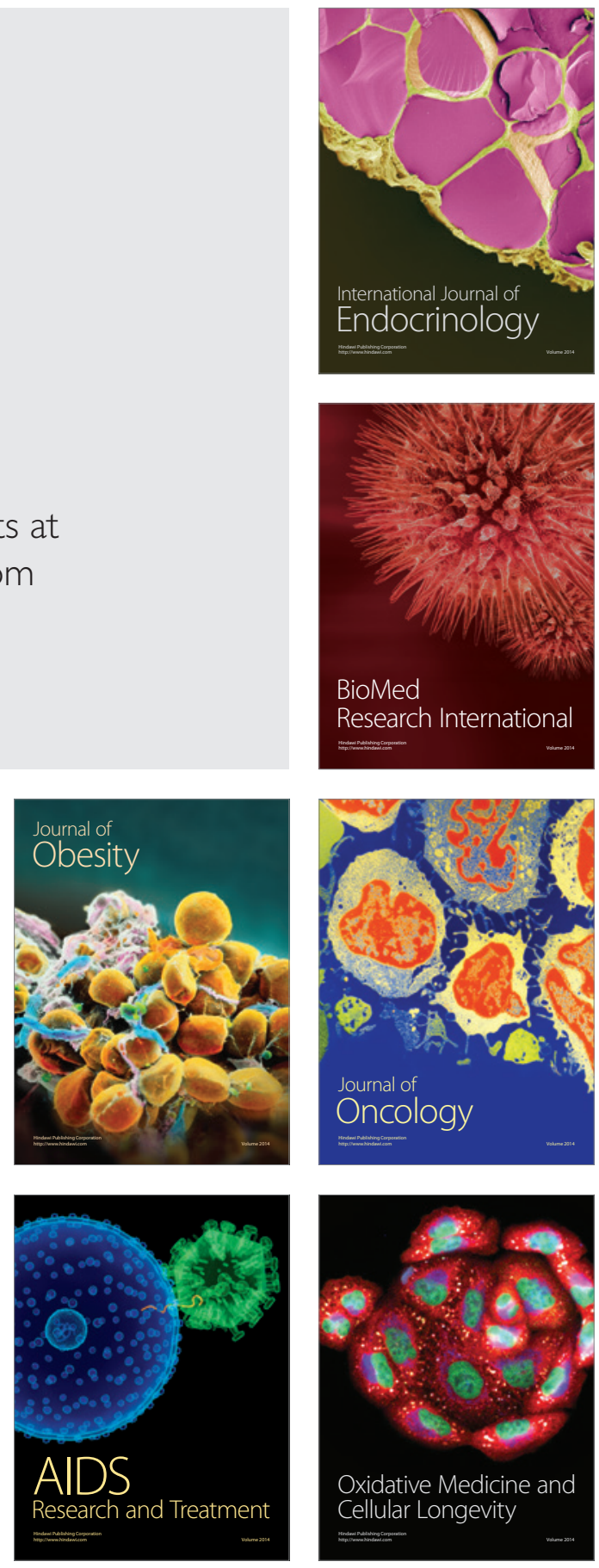